\title{
Pneumococcal immunization program in British Columbia: Past, present and future
}

\author{
Arlene King MD MHSc FRCPC on behalf of the Provincial Pneumococcal Immunization Working Groups*
}

The goal of British Columbia's pneumococcal immunization program is reduced morbidity and mortality caused by invasive pneumococcal disease in target groups for whom publicly funded pneumococcal vaccine is recommended by the National Advisory Committee on Immunization (1). Specific objectives set by the provincial working groups include a $50 \%$ reduction in the number of reported cases of invasive pneumococcal disease, and a 50\% reduction in hospitalizations and deaths due to invasive pneumococcal disease in those for whom vaccine is publicly funded by the year 2002 . At present, only pneumococcal meningitis is reportable in British Columbia; however, all presentations of invasive pneumococcal disease (defined as the isolation of Streptococcus pneumoniae from a normally sterile site) were made reportable in 1998.

Before 1996, there was limited use of pneumococcal vaccine in British Columbia, despite its availability since 1983. Although vaccine has been available free of charge to those over 65 years of age through the provincial drug benefits program, uptake has been poor. This has been due, at least in part, to the cumbersome nature of the process required to obtain the vaccine: an initial physician visit, a recommendation to the patient that he or she should receive pneumococcal vaccine, a patient visit to a pharmacy to obtain the vaccine and a subsequent visit to the physician's office for administration. Furthermore, this method of program delivery is inconsistent with other highly successful immunization programs in British Columbia, where there is government bulk purchase, distribution to local public health units and 'mixed' delivery by physicians and public health nurses.

In July 1996, government bulk purchase and distribution of pneumococcal vaccine began for those two years of age or older with anatomic and functional asplenia and for bone marrow transplant recipients. Subsequently, a proposal was presented to the Ministry of Health to expand this program to include all persons at increased risk of pneumococcal disease or its complications, including persons over 65 years of age and those two years of age or older with certain chronic conditions. Funding was approved to immunize long term care (LTC) facility residents beginning in November 1997 (phase 1) and to immunize persons age 65 years and older beginning in April 1998 (phase 2). A proposal to immunize remaining high risk groups from two to 65 years of age (phase 3 ) is under consideration by the Ministry of Health.

\section{PHASE 1: PNEUMOCOCCAL IMMUNIZATION OF LONG TERM CARE FACILITY RESIDENTS}

A working group to plan the implementation of phase 1 met initially in August 1997. At that time, pneumococcal immunization was offered in $12 \%$ of the LTC facilities that responded to an inquiry regarding their immune protocols. Although not

\footnotetext{
*Pneumococcal Immunization Working Group Members, Phase 1: Vicki Anderson, Alison Bell, Arlene King, Karen Pielak (British Columbia Ministry of Health, Victoria); Mark Bigham (Vancouver-Richmond Health Region, Vancouver); Barbara Hoffman (South Fraser Health Region, Surrey); Pauline Pigeau (Fraser Valley Health Region, Chilliwack); Robert Van Exan (Pasteur-Merieux Connaught, Toronto, Ontario); Lorna Willis (Dogwood Lodge, Vancouvers). Pneumococcal Immunization Working Group Members, Phase 2: Karen Ablog-Morrant and Menn Biagtan (British Columbia Lung Association, Vancouver); Mark Bigham and Shelagh Weatherill (Vancouver-Richmond Health Region); Bev Grunert (Okanagan-Similkameen Health Region, Kelowna); Roberta Hamilton (Cariboo Health Region, Williams Lake); Arlene King and Karen Pielak (British Columbia Centre for Disease Control Society, Vancouver); Yvonne Millward (Fraser Valley Health Region); Danuta Skowronski (South Fraser Health Region); Lorna Storbakken (British Columbia Ministry of Health); Robert Van Exan (Pasteur-Merieux-Connaught).

Correspondence and reprints: Dr Arlene King, British Columbia Centre for Disease Control, 655 - 12th Avenue West, Vancouver, British Columbia Y5Z 4R4. Telephone 604-660-3199, fax 604-660-0197, e-mail arlene.king@bccdc.hnet.bc.ca
} 
measured, vaccine coverage rates were judged to be low (2). The program objective was to achieve $80 \%$ vaccine coverage among LTC facility residents in British Columbia by January 1998. This objective was viewed to be feasible if the 'catch-up' program was delivered by LTC facility staff in conjunction with the annual November influenza immunization program. An objective of $90 \%$ coverage of LTC facility residents by January 1999 was also set. The working group developed a promotional strategy consisting of the following:

- a letter from the Provincial Health Officer to all LTC facility directors of care introducing the program;

- a question and answer document on pneumococcal disease, the vaccine and the program;

- a colour overhead presentation on the pneumococcal immunization program for use by public health staff and others to promote the program with health care providers; and

- a 'sample' letter to physicians from Medical Health Officers introducing phase 1 of the program.

Pneumococcal vaccine was bulk purchased by the British Columbia Centre for Disease Control Society and distributed concurrently with influenza vaccine to local health units. It was suggested that 'standing orders' for immunization of all new facility admissions be obtained where possible. Record keeping standards were developed. An adhesive chart 'spine' label for quick glance reference was distributed to all regional health authorities for optional use by LTC facilities.

The Ministry of Health collects, collates and analyzes data from regional health authorities to estimate immunization coverage rates in British Columbia. In early 1998, information on LTC facility pneumococcal vaccine coverage was requested from all health regions. The overall provincial vaccine coverage rate among LTC facility residents is $75 \%$ (reported range $49 \%$ to $95 \%$ ).

\section{PHASE 2: PNEUMOCOCCAL IMMUNIZATION} OF ALL PERSONS AGED 65 YEARS AND OLDER

In January 1998, a provincial working group was struck to implement phase 2 of the program. Funding was provided to conduct a catch-up campaign over three years, beginning in
April 1998. The tasks of the working group were to set coverage objectives for the program, outline a recommended promotional strategy, determine the logistics of vaccine distribution and administration, develop a standard of record keeping, and recommend an evaluation strategy.

In addition to the materials developed during phase 1 of the program, it was determined that posters for use in various health care settings would serve to remind health care providers and eligible clients of the availability of publicly funded vaccine. The program would also be promoted through articles in provincial nursing and medical journals. Because limited funding was available for vaccine delivery, regional differences were anticipated with respect to the start date and mode of delivery (public health nurses and/or physicians).

Immunization record keeping was discussed at some length. Because pneumococcal vaccine is generally given only once, an easily retrievable record of immunization is needed to avoid unnecessary reimmunization and adverse events. Strategies such as a patient chart sticker; wallet-sized, client-held immunization card; permanent medical card marker; and vaccinespecific health insurance plan code for use by physicians were considered by the working group.

To date, a number of problematic implementation issues have been discussed by working group members, including the feasibility of conducting a catch-up campaign in persons aged 65 years and older over three years, the advisability of promoting a program with limited new funds for vaccine delivery, and whether supporting the argument that savings generated from this program should offset physician and hospital care costs.

Most health authorities delayed implementation of phase 2 until November 1998, at which time pneumococcal vaccine was offered to those aged 65 years or older when they presented at influenza immunization clinics. Health authorities will submit their pneumococcal and influenza immunization coverage levels in March 1999.

\section{REFERENCES}

1. Health Canada. Canadian Immunization Guide, 4th edn. Ottawa: Publisher, 1993.

2. Bjornson G, Scheifele D, Lightle G, Bell A. Influenza and pneumococcal vaccine uptake rates in adults living in long term care facilities in British Columbia. BC Health Dis Surveil 1997;6:123-6. 


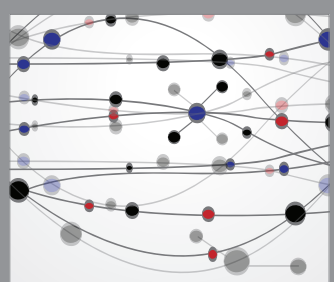

The Scientific World Journal


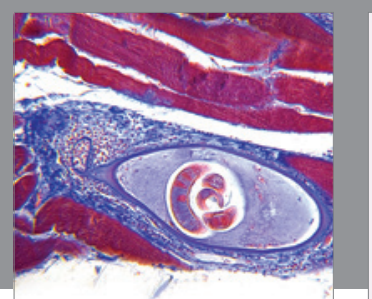

Gastroenterology Research and Practice

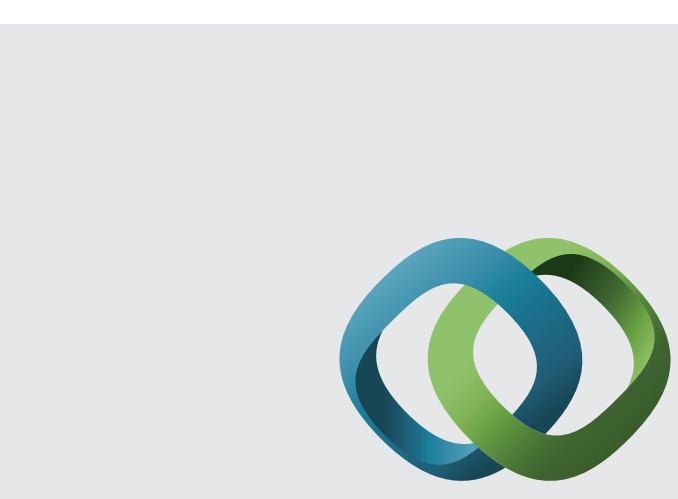

\section{Hindawi}

Submit your manuscripts at

http://www.hindawi.com

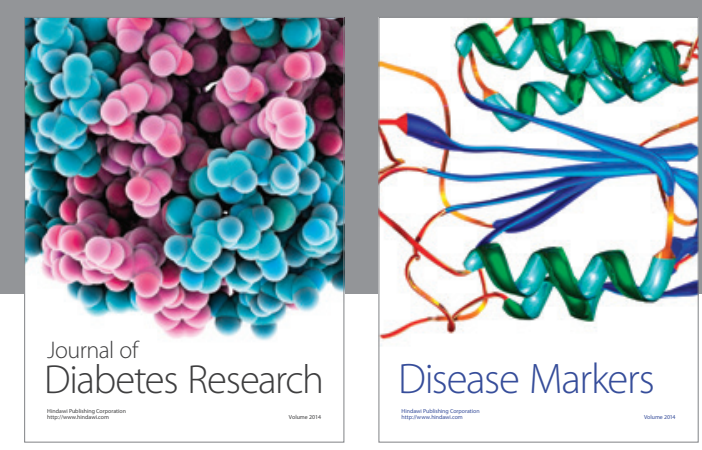

Disease Markers
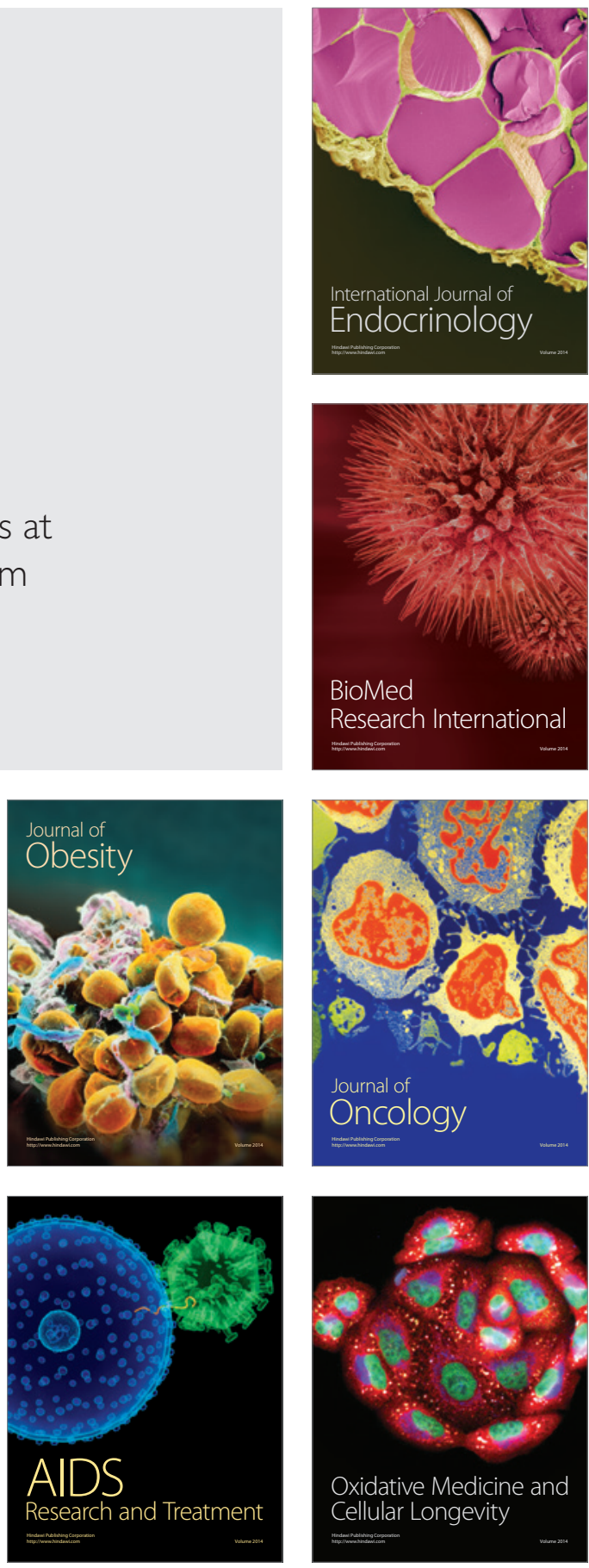